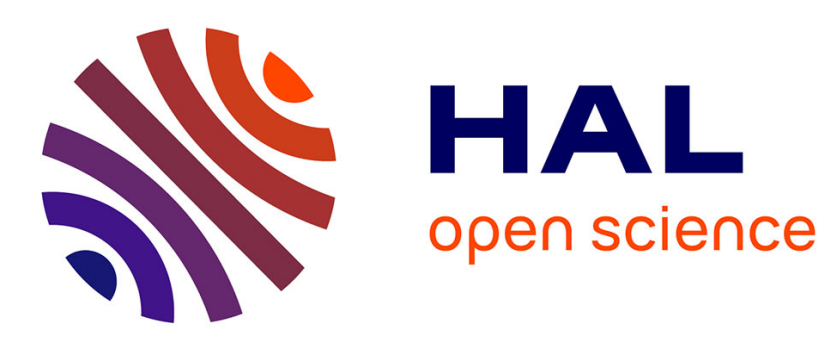

\title{
Ultrasoft Finemet thin films for magneto-impedance microsensors
}

Johan Moulin, Francisco Alves, I. Shahosseini, Frederic Mazaleyrat

\section{To cite this version:}

Johan Moulin, Francisco Alves, I. Shahosseini, Frederic Mazaleyrat. Ultrasoft Finemet thin films for magneto-impedance microsensors. Journal of Micromechanics and Microengineering, 2011, 21, pp.074010. 10.1088/0960-1317/21/7/074010 . hal-00608888

\section{HAL Id: hal-00608888 \\ https://hal.science/hal-00608888}

Submitted on 19 Jul 2011

HAL is a multi-disciplinary open access archive for the deposit and dissemination of scientific research documents, whether they are published or not. The documents may come from teaching and research institutions in France or abroad, or from public or private research centers.
L'archive ouverte pluridisciplinaire HAL, est destinée au dépôt et à la diffusion de documents scientifiques de niveau recherche, publiés ou non, émanant des établissements d'enseignement et de recherche français ou étrangers, des laboratoires publics ou privés. 


\title{
Ultrasoft Finemet thin films for magneto-impedance microsen- sors
}

\author{
J. Moulin ${ }^{1}$, I. Shahosseini ${ }^{1}$, F. Alves ${ }^{2}$, F. Mazaleyrat ${ }^{3}$ \\ ${ }^{1}$ IEF, UMR 8622, CNRS /Univ Paris Sud, F-91405 Orsay, France \\ 2 LGEP, UMR 8507, CNRS / Univ Paris Sud / Supelec, F-91192 Gif-Sur-Yvette, France \\ ${ }^{3}$ SATIE, UMR 8029, CNRS / ENS Cachan, F-94235 Cachan, France \\ johan.moulin@u-psud.fr \\ iman.shahosseini@u-psud.fr \\ francisco.alves@lgep.supelec.fr \\ frederic.mazaleyrat@satie.ens-cachan.fr
}

\begin{abstract}
FeCuNbSiB thin films have been deposited using RF sputtering. Characterizations have shown that oxygen contamination and residual stress are mainly responsible for magnetic hardening. The sputtering and annealing conditions have been optimized and films with coercive field as low as $10 \mathrm{~A} \mathrm{~m}^{-1}(0.125 \mathrm{Oe})$ have been achieved. In addition, the influence of film thickness on the magnetic properties has been studied. Thus, magnetic field microsensors based on the magneto-impedance effect have been fabricated by stacking up Finemet/copper/Finemet films. The highest sensitivity (4000 V/T/A) is reached for $750 \mathrm{~nm}$ thick films. It is in the same range as cm-sized macroscopic devices realized using $20 \mu \mathrm{m}$ thick ribbons.
\end{abstract}

\section{Introduction}

Since the discovery of the magneto-impedance (MI) effect in amorphous microwires [1] and films [2], magnetic field sensors based on this property have become competitive with other techniques like GMR and fluxgates. Two domains of application are emerging: Non Destructive Testing using eddy current for the detection of microdefects in conductive sheets [3] and the detection of magnetic nanoparticules for biomedical applications $[4,5]$. NDT involves the measurement of the stray field generated by eddy currents induced in the conductive sheet to be controlled. A magnetic cartography allows detecting the deformation of the stray field induced by the presence of a defect in the material. Classical techniques involve pick-up coils. However, for detection of deep defect (typ. $10 \mathrm{~mm}$ deep), the frequency of the eddy current (thus of the stray field) is low (some tens of $\mathrm{Hz}$ ). In addition, the stray field is very weak. In this case, pick-up coils are not suitable and GMI sensor are good candidates.

The MI effect finds its origin in the variation of the skin depth $\delta$ with an applied magnetic field $\mathrm{H}_{\text {ext }}$ (through the magnetic permeability) while exciting the conductor using a high frequency current:

$$
\delta\left(\mathrm{H}_{\mathrm{ext}}\right)=\sqrt{\frac{\rho_{\mathrm{e}}}{\pi \mathrm{f} \mu_{\mathrm{t}}\left(\mathrm{H}_{\mathrm{ext}}\right)}}
$$

with $\mathrm{f}$ the excitation frequency, $\rho_{\mathrm{e}}$ the electrical resistivity and $\mu_{\mathrm{t}}$ the transversal (or rotational in case of a wire) magnetic permeability.

The impedance of the conductor depends on its geometry:

$$
\mathrm{Z}=\mathrm{R}_{\mathrm{dc}} \frac{\mathrm{ka}}{2} \frac{\mathrm{J}_{0}(\mathrm{ka})}{\mathrm{J}_{1}(\mathrm{ka})}
$$

for a wire [6], with $\mathrm{J}_{0}$ and $\mathrm{J}_{1}$ the Bessel function, $\mathrm{R}_{\mathrm{dc}}$ the $\mathrm{DC}$ resistance of the wire, $a$ the wire radius and $\mathrm{k}=(1-\mathrm{j}) / \delta$, or :

$$
\mathrm{Z}=\mathrm{R}_{\mathrm{dc}} \frac{\mathrm{ka}}{2} \operatorname{coth}(\mathrm{ka})
$$

for a thin film [7], where $a$ is the film thickness.

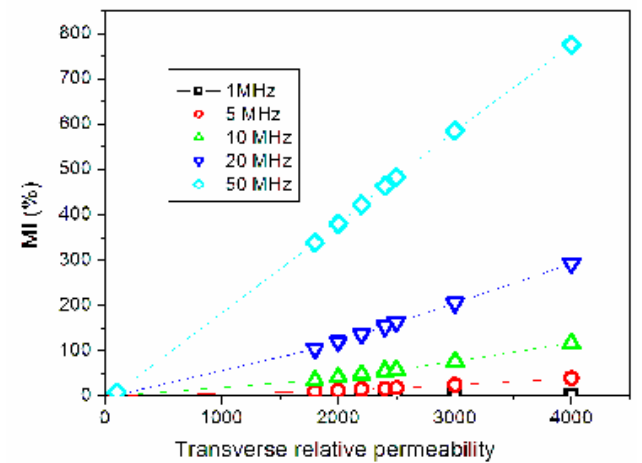

Figure 1: Finite elements calculation of the magnetoimpedance as a function of the transverse permeability of the ferromagnetic layer. Dimensions correspond to G500. 


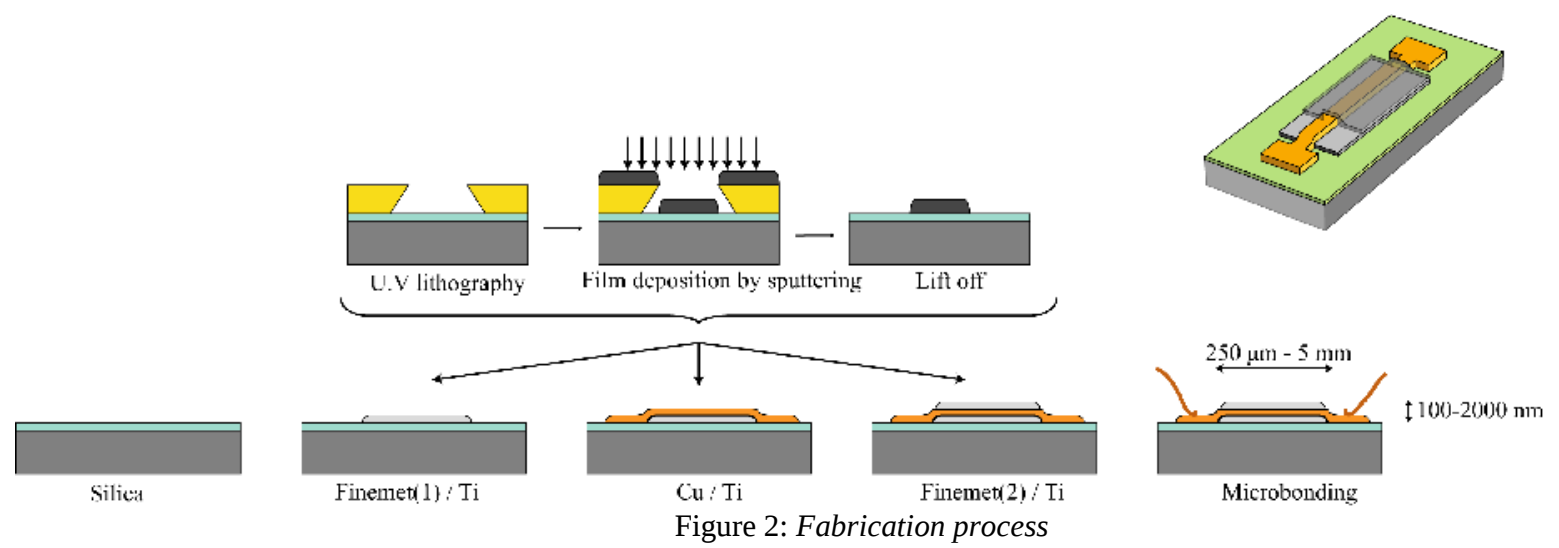

For both geometries, the calculation of the derivative of the modulus of $Z$ with the value $a / \delta$ shows that the variations of $Z$ are the most sensitive to the one of $a / \delta$ for $a / \delta \approx 2$, i.e. a $\approx 2 \delta$. It corresponds to an optimal excitation frequency for a given geometry. The highest MI ratios are obtained in amorphous Febased microwires, in which external and internal stresses are respectively circumferential and axial. This stress orientation corresponds to an optimal magnetic structure. However, collective fabrication, for instance in case of sensors arrays, is much easier while using thin films technique. It has been found that for a planar structure the MI variations can increase strongly by inserting a conductive film between the ferromagnetic layers [8]. In the case on large plates allowing neglecting border effect, the impedance on the trilayer structure can be expressed as:

$$
\begin{gathered}
Z=R_{D C}\left(\zeta k_{1} d_{1}+k_{2} d_{2}\right) \frac{\operatorname{coth}\left(k_{1} d_{1}\right) \operatorname{coth}\left(k_{2} d_{2}\right)+\zeta}{\operatorname{coth}\left(k_{1} d_{1}\right)+\zeta \operatorname{coth}\left(k_{2} d_{2}\right)} \\
\zeta^{2}=\frac{\rho_{e 2} \delta_{1}}{\rho_{e 1} \delta_{2}}=\frac{\rho_{e 2} \mu_{t}}{\rho_{e 1}} \quad k_{i}=\frac{(1-j)}{\delta_{i}} \quad i=1,2
\end{gathered}
$$

with $2 d_{1}$ and $d_{2}$ the thicknesses of the ferromagnetic and conductive layers respectively [9].

In this multilayer structure, the optimal excitation frequency for obtaining $\left(\Delta \mathrm{Z} / \mathrm{Z}_{\text {sat }}\right)_{\max }$ is much lower than for a single film, as the conductivity of common ferromagnetic materials is about 100 times lower than that of a good conductor. Previous calculations using finite elements method on such a structure [10] have shown that the highest MI effect is obtained around $10 \mathrm{MHz}$ for a $1 \mu \mathrm{m}$ thick ferromagnetic film with a relative permeability of 4000 with a thickness ratio of 1/2/1 for the multilayer structure. In addition, if the magnetic domains are oriented perpendicularly to the applied magnetic field, the MI rises because of the increase in transverse permeability in the ferromagnetic layers. For that purpose, the ferromagnetic layers were annealed under transverse magnetic anisotropy field.

The sensor characteristics, in particular hysteresis and sensitivity, are firmly dependent on the ferromagnetic layer softness. Figure 1 presents numerical calculations using finite elements for a G500 sensor configuration (see table 1 for dimensions). The MI increases quite linearly with the transverse permeability, which shows the importance of depositing a soft material. Several works have succeeded in integrating Finemet ${ }^{\circledR}$ alloys into thin film MI sensors [11-14]. Indeed, this material presents ultrasoft properties due to its microstructure: after a heat treatment of the amorphous precursor, ferromagnetic Fe-Si nanograins nucleate in a ferromagnetic matrix which remains amorphous. This ensures quasi-null magnetostrictive anisotropy by the means of negative and positive magnetoelastic effects balance between grains and matrix. Moreover, the magnetocristalline anisotropy in such nanocristalline materials is decreased following the Random Anisotropy Model proposed by Herzer [15].

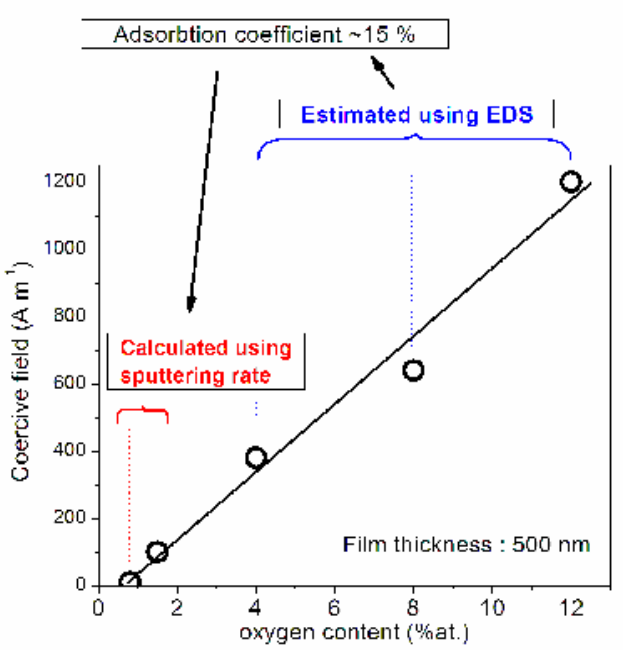

Figure 3: Influence of oxygen contamination on the coercive field

despite the fact that the developed sensors 
present lower MI ratios than those with FeCo-based alloys. However, MI ratio is not the only quality determinant factor for a sensor, variation of the MI with the magnetic field is more relevant. For this purpose, ultra-soft Finemet, which can be obtained by an optimization of the elaboration process, is a good candidate.

\section{Sensors elaboration process}

We developed a MI microsensor fabrication process compatible with thicknesses close to $1 \mu \mathrm{m}$. Each layer of the sensors was patterned using lift-off technique with a $3 \mu \mathrm{m}$ thick AZ5214 photoresist (see figure 2). In order to obtain such thick resist, the rotation speed during spin coating was limited to $900 \mathrm{rpm}$. The lithography exposure dose and development time were also adapted to such a thickness. The materials were deposited using sputtering technique: Finemet ${ }^{\circledR}$ and copper for the ferromagnetic and conductive layers respectively. The Finemet has been deposited on a SiO2/Si substrate by RF sputtering in Ar plasma under the following conditions: residual pressure in the range of $10^{-7} \mathrm{mbar}$, working pressure $40 \mathrm{mbar}$ and RF power $250 \mathrm{~W}$. The copper layer was realized by DC sputtering with a working pressure of $6.5 \mathrm{mbar}$ and a power of $50 \mathrm{~W}$. Before each sputtering, a $10 \mathrm{~nm}$ thick layer of titanium was deposited in order to increase adhesion.

The sensors are constituted of rectangular stripes whose dimensions vary from 50 to $430 \mu \mathrm{m}$ in width and from 1 to $5 \mathrm{~mm}$ in length. For our samples, we attempt to obtain a central copper layer totally shielded by ferromagnetic layers, i.e. the Finemet layers are wider than the copper track. However, the latter is longer and is ended by two connection pads for bonding.
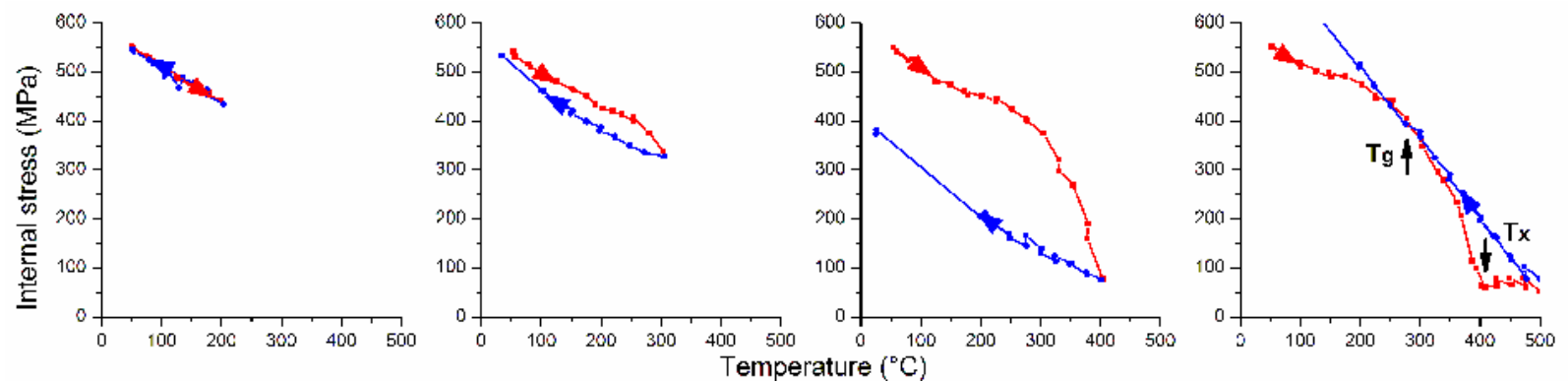

Figure 4: Internal stress of a $500 \mathrm{~nm}$ thick continuous Finemet film deposited on a 2" wafer during heating (red) then cooling (blue)

\section{Finemet elaboration process}

\subsection{Sputtering conditions}

In order to obtain the lowest coercivity, the magnetic properties of the Finemet ${ }^{\circledR}$ films have been optimized in terms of elaboration and heat treatment. Former study has showed that the coercivity is mainly influenced by the oxygen contamination and the residual stresses in the films [16].

The former is correlated to the deposition conditions. In practice, the deposition time has been minimized in order to limit oxygen contamination. This implies a short distance between the target and the sample, as well as a high argon pressure. In addition, a liquid nitrogen trap is needed. Fig. 3 shows that the coercive field follows quite linearly the content in oxygen in the film. The reader can refer to [17] for details on the measurement of the composition.

The stress in the films has two origins: the atomic disorder induced by the deposition and the differential thermal expansion between the substrate and the film (difference between room and process temperature). The measurement of the wafer curvature using a laser scanning yields an estimation of the internal stress of a 2" continuous film as a function of temperature (heating and cooling rates are about $2.5^{\circ} \mathrm{C} / \mathrm{min}$ ). Figure 4 presents the results for different final temperatures: $200,300,400$ and $500^{\circ} \mathrm{C}$. The stress induced by the deposition is high (around $550 \mathrm{MPa}$ for a 2" continuous film) due to particular sputtering con-

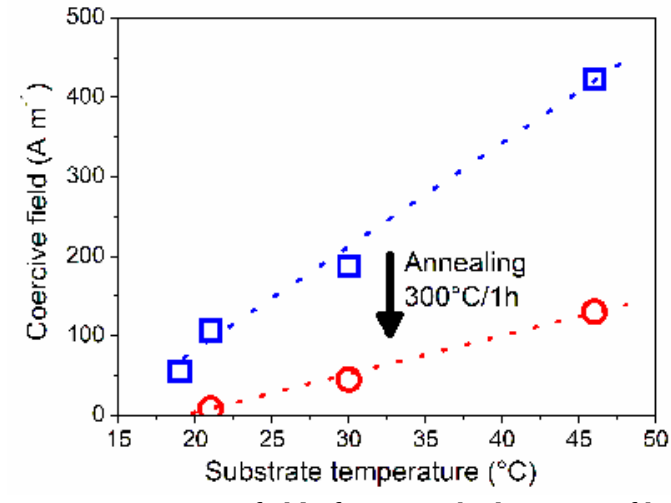

Figure 5: Coercive field of $500 \mathrm{~nm}$ thick Finemet films as a function of the substrate temperature at the beginning of the sputtering 
ditions and does not depend on the film thickness (from 200 $\mathrm{nm}$ to $2 \mu \mathrm{m}$ ). It can be reduced by annealing only. MOKE characterizations on large samples (several $\mathrm{cm}^{2}$ ) have revealed planar isotropic behavior and gave an estimation of the coercive field of $4.6 \mathrm{kA} \mathrm{m}^{-1}$, what is consistent with large stress in the film. In case of non-continuous films, it is supposed that the residual stress due to sputtering is drastically reduced. The films have been patterned by mean of shadow masking for magnetic characterization using AGFM or VSM ( $2 \mathrm{~mm} \times 2 \mathrm{~mm}$ squares). The coercive field (measured using AGFM or VSM) is in that case lowered down to $60 \mathrm{~A} \mathrm{~m}^{-1}$. This result shows that the patterned film is subjected to lower stress than its continuous counterpart. It is however difficult to estimate the stress in the pattern, except by indirect method. Considering that the stress is the only responsible for the increasing of the coercive field, one can estimate that the stress is reduced down to several MPa after patterning.

As this state, the material is subjected to secondary process conditions, like the initial temperature of the substrate (sample is not cooled in our equipment). Indeed, the differential thermal expansion between the substrate and the film during the cooling after the deposition is responsible for stress:

$$
\sigma_{\text {therm exp }}=\left(\mu_{w}-\mu_{f}\right) \frac{E_{f}}{1-v_{f}}(\Delta T)=\alpha(\Delta T)
$$

with $\mu_{\mathrm{w}}, \mu_{\mathrm{f}}, \mathrm{E}_{\mathrm{f}}, \nu_{\mathrm{f}}$ and $\Delta \mathrm{T}$ respectively the thermal expansion coefficients of the substrate and the film, Young's modulus and Poisson's ratio of the film and the temperature variation involved in the thermal expansion process.

This stress influences strongly the magnetic properties of the films. The figure 5 shows that the coercive field of $2 \mathrm{~mm} \times 2$ $\mathrm{mm}$ squares deposited at the same residual vacuum varies quite linearly with the initial temperature. This phenomenon can be related to an increasing of the global anisotropy induced by magnetoelastic effect. The magnetoelastic anisotropy associated to an amorphous material is:

$$
\mathrm{E}_{\mathrm{s}}=\frac{3}{2} \lambda_{\mathrm{s}} \sigma
$$
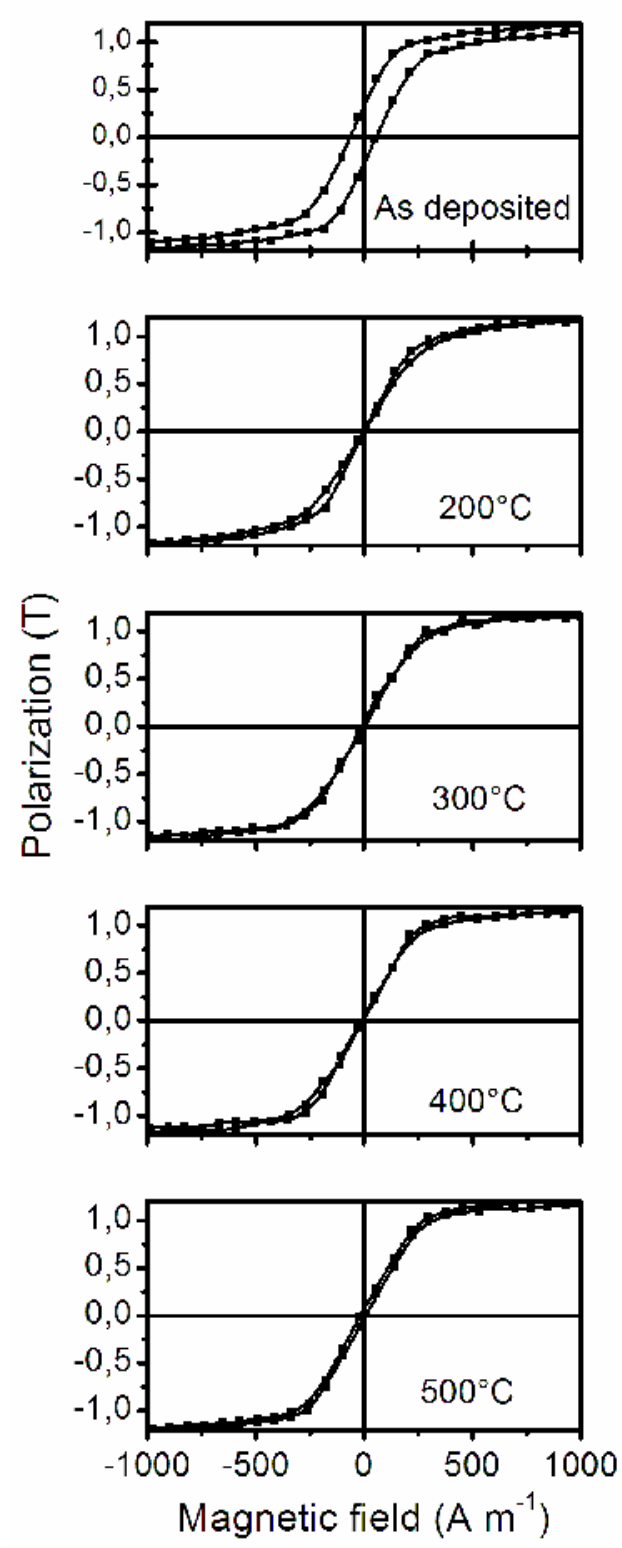

Figure 6. Hysteresis loops of $500 \mathrm{~nm}$ Finemet film annealed for $1 \mathrm{~h}$ at various temperature.

with $\lambda_{\mathrm{s}}$ the saturation magnetostriction coefficient and $\sigma$ the global stress in the film. In case the thermal expansion only is responsible of stress variations, the magnetoelastic energy thus the coercive field varies linearly with the difference of temperature during sputtering and ambient temperature. Indeed, in the case of randomly oriented stress without anisotropy of form or crystal [18]:

$$
\mathrm{H}_{\mathrm{c}}=0.64 \frac{\mathrm{E}_{\mathrm{s}}}{\mathrm{J}_{\mathrm{s}}}
$$

with $\mathrm{J}_{\mathrm{s}}$ the saturation magnetization of the material.

Finally, one obtains a linear relation between the coercive field and the difference between the initial temperature of the substrate and the room temperature:

$$
\mathrm{H}_{\mathrm{c}}=0.96 \frac{\lambda_{\mathrm{s}}}{\mathrm{J}_{\mathrm{s}}} \alpha(\Delta \mathrm{T})
$$

what has been experimentally measured.

Figure 4 presents the results for different final temperatures: 200, 300, 400 and $500^{\circ} \mathrm{C}$. From this work, the coefficient $\alpha$ in Eq. (8) has been estimated about $0.75 \mathrm{MPa} / \mathrm{K}$ while the temperature remains below 
$200^{\circ} \mathrm{C}$. Indeed, in this range of temperature, the heating and cooling curves are superposed thus thermal expansion only is responsible for stress variations in the film. Using the magnetostriction coefficient and the saturation magnetization of such alloys (i.e. $\lambda_{\mathrm{s}}=2310^{-6}$ and $\mathrm{J}_{\mathrm{s}}=1.2 \mathrm{~T}$ ), one can estimate the increasing of the coercive field due to thermal expansion in the range of $13.6 \mathrm{~A} \mathrm{~m}^{-1} / \mathrm{K}$. This is coherent with the

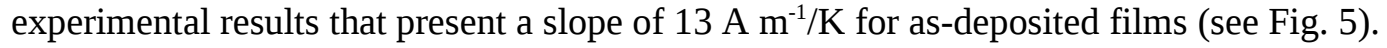

After an annealing at $300^{\circ} \mathrm{C}$ for $1 \mathrm{~h}$, the dependence of the coercive field on the initial substrate temperature is also linear, what reflects a similar behavior, except that the slope is reduced to $5 \mathrm{~A} \mathrm{~m}^{-1} / \mathrm{K}$. This result is associated to a reduction of $\lambda_{\mathrm{s}}$ due to a modification of the microstructure.

\subsection{Annealing}

The remaining stress has to be minimized in order to obtain softer films. This is one of the roles of postannealing.

The figure 6 presents the hysteresis loops of $500 \mathrm{~nm}$ films annealed at various temperatures for $1 \mathrm{~h}$. The coercive field decreases strongly after annealing at $200^{\circ} \mathrm{C}$. Above this temperature, the coercive field decreases slightly, down to 10 A $\mathrm{m}^{-1}$ for annealing at $400^{\circ} \mathrm{C}$. At $500^{\circ} \mathrm{C}$, The coercive field drops to $15 \mathrm{~A} \mathrm{~m}^{-1}$. Similar results have been obtained with a minimum coercive field at $280-330,380$ and $450^{\circ} \mathrm{C}$ for 50,1000 and 2000 nm respectively [19-21]. Compare to these works, the characteristic temperatures of the film have been precisely defined using the measurement of the stress in the film as a function of the temperature, during heating and cooling. From Fig. 5, two particular temperatures can be extracted. The glassy transition temperature Tg corresponds to the limit with the supercooled liquid state in which the effect of the differential thermal expansion is reduced. Thus Tg corresponds to the first slope changing in the heating curve: $300^{\circ} \mathrm{C}$ for a $500 \mathrm{~nm}$ thick film. The cooling curve shows that the mechanical properties (Young's modulus and Poisson ratio) of the material are not changed while the final temperature remains below $400^{\circ} \mathrm{C}$. The second slope breaking corresponds to an evolution of the microstructure leading to a new Young modulus value, i.e. crystallization. It is to notice that the crystallization temperature decreases with the film thickness [16], from 480 to 450 and $400{ }^{\circ} \mathrm{C}$ for 20,2 and $0.5 \mu \mathrm{m}$ respectively. These results are coherent with values measured using other technics in [19-21].

The magnetic behavior is partially correlated to these measurements. Indeed, the minimum coercive field is reached for an annealing temperature equal to the crystallization temperature $T_{x}$. At this state, stresses are released and nanograins of Fe-Si have nucleated but crystalline volume fraction remains small. The obtained nanostructure leads to an averaging out of the magnetocrystalline anisotropy, according to the Random Anisotropy Model [22]. Above $T_{x}$, the modification of the mechanical properties (especially Young's modulus) induces large residual stress due to differential thermal expansion during the cooling, thus to an increasing of the coercivity. However, the magnetic behavior of samples annealed at $200^{\circ} \mathrm{C}$ can not be explained using stress measurement of a continuous film. Indeed, the drastic decreasing of the coercive field is not correlated to an obvious modification of the mechanical properties of the film between room tempera-
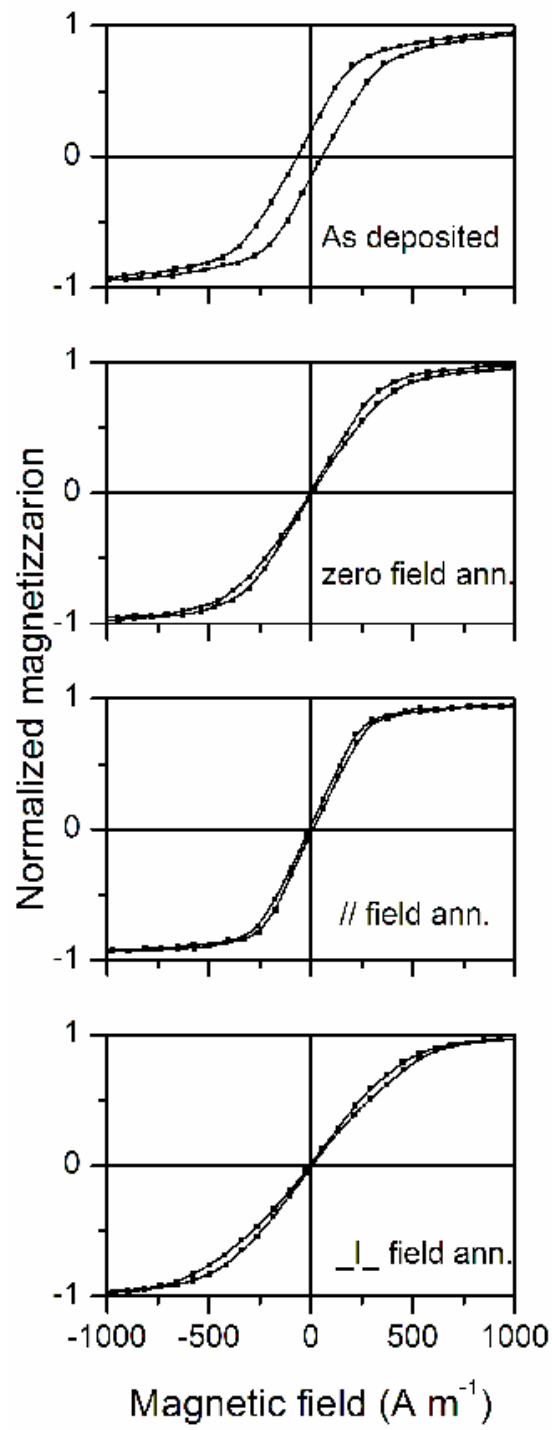

Figure 7: Influence of field annealing at $300^{\circ} \mathrm{C}$ on hysteresis loops of $500 \mathrm{~nm}$ thick samples ture and $200^{\circ} \mathrm{C}$.

It is to notice that the relative permeability, as well as the saturation polarization are not affected by the annealing and remains constant with values of $1.2 \mathrm{~T}$ and 3400 respectively. 


\subsection{Field induced anisotropy}

As reported in other works [23], the MI sensor sensitivity is increased after inducing an anisotropy perpendicular to the current direction in the ferromagnetic material. This has been performed by annealing in the magnetic field created by a $3 \mathrm{~mm}$ thick and $5 \mathrm{~cm}$ diameter magnetic circuit containing AlNiCo magnets. The magnetic field in the $7 \mathrm{~mm} \times 14 \mathrm{~mm}$ air gap where samples were set out is in the range of 50 $\mathrm{kA} \mathrm{m}^{-1}$. The AlNiCo magnets allow working up to $500^{\circ} \mathrm{C}$ in the secondary vacuum of the sputtering chamber. Figure 7 depicts the hysteresis loops of $2 \mathrm{~mm} \times 2 \mathrm{~mm} \times 500 \mathrm{~nm}$ samples realized by shadow masking and characterized using AGFM. The field induced anisotropy leads low coercive field, as well as annealing without magnetic field: $10 \mathrm{~A} \mathrm{~m}^{-1}$ for zero and // field annealing and $15 \mathrm{~A} \mathrm{~m}^{-1}$ for $\perp$ field annealing. The induced anisotropy can be estimated from loops measured in both the parallel and perpendicular directions of the annealing magnetic field. Its value is in the range of $150 \mathrm{~J} \mathrm{~m}^{-3}$, much larger than that induced in bulk materials by this technique. In addition, the anisotropy field can be estimated to 4350, 300

Table 1. Dimensions of the sensors

\begin{tabular}{cccc}
\hline & $\begin{array}{c}\text { Film thickness } \\
(\mathrm{nm})\end{array}$ & $\begin{array}{c}\text { Finemet }(\mu \mathrm{m}) \\
\text { G500 }\end{array}$ & $\begin{array}{c}\text { Copper }^{a} \\
(\mu \mathrm{m})\end{array}$ \\
\hline G750 & $750 / 500 / 500$ & $4000 \times 200$ & $4200 \times 50$ \\
B1000 & $1000 / 1000 / 1000$ & $4000 \times 200$ & $4200 \times 50$ \\
\hline
\end{tabular}

${ }^{a}$ electrical pads are not taken into account and $700 \mathrm{~A} \mathrm{~m}^{-1}$ for zero, // and $\perp$ field annealing respectively. The induced energy is correlated to a variation of the permeability: 2300, 3000 and 1300 for zero, // and $\perp$ field annealing respectively.

After optimization of the ferromagnetic material properties, sensors with variable sizes and thicknesses have been processed as listed in table 1.

\section{Sensors characteristics}

MI measurements have been carried out using a voltage source and a lock-in amplifier in the 1-40 MHz frequency range. The DC magnetic field measured by the sensor was created by a set of Helmholtz coils, providing a $2 \mathrm{~cm}$ wide homogeneous field zone. The maximum magnetic field applied to the sensor is close to $7000 \mathrm{~A} \mathrm{~m}^{-1}$.

The MI ratio variations are weak compared to other type of sensors, in the range of $10 \%$. Indeed, the resistance value is large (around $10 \Omega$ ) and varies little. By opposition, the inductance variations reach 400 $\%$ but the inductance value is low. These measurements highligth magnetic properties like anisotropy field, which is in the range of $700 \mathrm{~A} \mathrm{~m}^{-1}$ for sensors G500 and G750. The result is coherent with the value estimated from the hysteresis loop of the films annealed under transverse magnetic field.

Papers related to MI effect generally compare the materials properties using the MI ratio only. However, this is not the most relevant factor to quantify a sensors quality. The most important figure is either the variation of the MI ratio with the magnetic field (in \%/Oe) or the variation of the impedance with the magnetic field (in $\Omega / T$ or in $\mathrm{V} / \mathrm{T} / \mathrm{A}$ ).

Furthermore, measurements at high frequency are strongly sensitive to external perturbations, so the impedance value can be unreliable. To solve this problem, the sensors were characterized by measuring the output voltage as a function of the magnetic field, starting from the saturated state. Then the sensitivity was extracted by numerical derivation of the voltage by the magnetic field.

The characterizations have highlighted a strong dependence of MI properties on the shielding of the central copper track by the ferromagnetic material. Former investigation has shown that defects at the edge of the

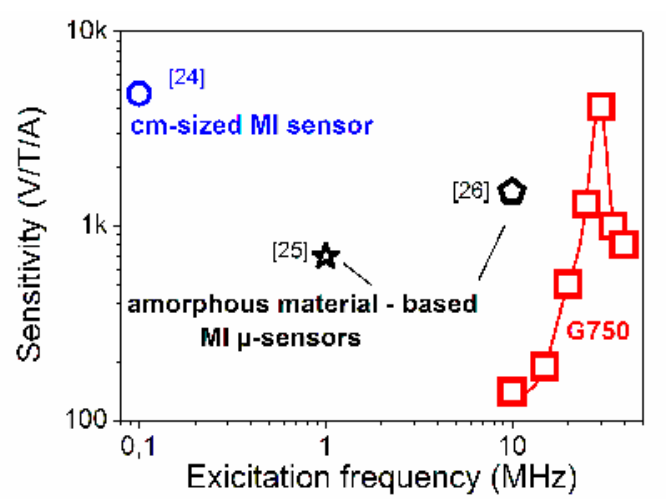

Figure 8: Dependence of the G750 sensor maximum sensitivity on the excitation frequency. Comparison with other amorphous material-based MI sensors deposited layer appear while the sputtering direction is not vertical enough. This phenomenon is related to the deposition of the sputtered material on the side of the photoresist for thick film and high working pressure. The consequence of this defect on the properties depends on the involved layer and can be a lack of shielding for the central copper track or an over-di- 
mensioning of the sensor for the Finemet layers. The former reduces the effect of the transverse induced anisotropy, as the upper Finemet layer is separated in three magnetically independent parts, whereas the latter impedes down-sizing of the sensor and thus limits the spatial resolution.

The sputtering conditions of copper have been optimized in order to limit over-deposition at the edge of the central conductive track. Thus the upper Finemet layer is continuous and provides magnetic shielding of the copper track. However, the defects at the edge of the finemet layer are not yet eliminated, as deposition conditions are driven by the minimization of the coercivity. Their influence on MI properties is theoretically weak, as calculated by digital simulation. However, these defects act as pinning centers for the magnetic domains movement and reduce the sensitivity of the device.

Sensors with variable dimensions and thicknesses have been realized (see table 1). Digital simulations predict, for a given excitation frequency, an increase in the sensitivity with the films thickness. Indeed, experimental characterizations show that the maximal sensitivity increases from $1900 \mathrm{~V} / \mathrm{T} / \mathrm{A}$ for the G500 sensor to $4100 \mathrm{~V} / \mathrm{T} / \mathrm{A}$ for the G750 sensor. Unfortunately, the size of defect above the copper track increases with the film thickness. This results in a low sensitivity for the sensor B1000.

Fig. 8 presents the maximum sensitivity of the G750 sensor as a function of the frequency with a $1.7 \mathrm{~mA}$ excitation current. It reaches a maximum at $30 \mathrm{MHz}$. This optimal frequency is slightly larger than expected (in the range of $20 \mathrm{MHz}$ for such thicknesses) what is supposed to be linked to an overestimation of $\mu_{\mathrm{t}}$ in the calculation. Below this optimal frequency, the skin depth is larger than the film thickness thus the ferromagnetic film is poorly sensitive to skin effect. At the opposite, high frequency excitation current induces a skin effect located at the surface of the film and the magneto-impedance suffers from a magnetic hardening due to surface anisotropy. On the same figure, the results are compared to $\mathrm{FeCoSiB} / \mathrm{Cu} / \mathrm{Fe}$ $\mathrm{CoSiB}$ [22] and $\mathrm{FeSiB} / \mathrm{Cu} / \mathrm{FeSiB}$ [23] MI microsensors whose sensitivity and excitation frequency are smaller. Results are also compared to the sensitivity of a macrosensor realized with Finemet and copper ribbons which thicknesses are $20 \mu \mathrm{m}$ and $40 \mu \mathrm{m}$ respectively. The total size of the sensor is $5 \mathrm{~cm} \mathrm{x} 1 \mathrm{~cm}$. It is noticeable that there is no drastic decrease of the sensitivity due to scale effect. Indeed, the structures of both the macro-sensor and the present devices are comparable. The maximal sensitivities are in the same range. However, the optimal frequency increases from $100 \mathrm{kHz}$ to $30 \mathrm{MHz}$ for the macro- and microsensors respectively, due to the thickness reduction.

\section{Conclusion}

This paper reports a technological process for depositing ultrasoft Finemet thin films using a common technique. In addition, it has been shown that this material can be integrated in MI microsensors. The sensitivity can reach $4100 \mathrm{~V} / \mathrm{T} / \mathrm{A}$, which is the largest among all published similar structures.

The results highlight the strong dependence of the sensor quality on the presence of a defect above the copper track which stems from the association of lift-off and non directive sputtering of thick films. In future works, strength will be put on the removal of this defect, for instance using a specific lift-off resist dedicated to thick film deposition.

The optimal excitation frequency for the sensor G750 is $30 \mathrm{MHz}$, which remains high for standard electronic. Thicker films will allow decreasing this frequency to $10 \mathrm{MHz}$.

\section{Acknowledgment}

This work has been financially supported by the French Agence Nationale pour la Recherche, through the Project IMAGINE and by the Conseil Général de l'Essone through the use of the equipments of the Centrale de Technologie Universitaire IEF-MINERVE.

\section{References}

[1] Panina L V, Mohri K, Uchiyama T, Bushida K and Noda M 1995 IEEE Trans. Mag. 311249

[2] Panina L V, Mohri K, Bushida K, and Noda M 1994 J. Appl. Phys. 766198

[3] Vacher F, Alves F and Gilles-Pascaud C 2007 NDT \& E International 40 (6), 439

[4] Blanc-Beguin F et al. 2009 J. Magn. Magn. Mater 321192

[5] Chiriac H, Tibu M, Moga A-E and Herea D 2005 J. Magn. Magn. Mater 293671

[6] Landau L D, Lifshitz E M 1975 Electrodynamics of continuous media (Oxford: Pergamon)

[7] Kittel C 1946 Phys. Rev. 70 (5-6) 281 
[8] Senda M, Ishii O, Koshimoto Y and Toshima T 1994 IEEE Trans. Mag. 30 (6) 4611

[9] Panina L V, Mohri K 2000 Sensors and actuators 8171

[10] Moulin J et al. 2009 Sensor Letters 7 (3)

[11] Xiao S Q et al. 2000 Phys. Rev. B 61 (8) 5734

[12] Chen J A et al. 2006 Mat. Lett. 602554

[13] Correa, M A, Viegas, A D C, Da Silva R V, De Andrate A M H and Sommer R L 2007 J. Appl. Phys. 101 (4) 043905

[14] Li X D, Yuan W Z, Zhai Z J, Ruan J Z and Yang X L 2004, J. Phys. D: Appl. Phys. 381351

[15] Herzer G 1993 Physica Scripta T49 307

[16] Moulin J, Ammar M, Shah-Hosseini I, Alves F and Mazaleyrat F 2010 J. Phys. Conf. Series 200 (8) 082020

[17] Moulin J et al. 2009, Solid State Phenomena 152-153 3

[18] Bozorth R Ferromagnetism 1951 (New York: Van Nostrand Company)

[19] Sharma P and Gupta A 2005, J. Magn. Magn. Mater 288347

[20] Neuweiler A and Kronmüller H 1998, J. Magn. Magn. Mater 177-181 1269

[21] Li X D et al. 2004, J. Magn. Magn. Mater 279429

[22] Moulin J, Mazaleyrat F, Mendez A and Dufour-Gergam E 2010 J. Magn. Magn. Mater 322 (9-12) 1275

[23] Wang W J et al. 2005 Thin Solid Films 484299

[24] Alves F, Moutoussamy J, Coillot C and Abi-rached L 2008 Sens. actuators. A 145-146 241

[25] Nishibe Y, Yamadera H, Ohta N, Tsukada K and Nonomura Y 2000 Sens. Actuators 82155

[26] Morikawa T, Nishibe Y, Yamadera H, Nonomura Y, Takeuchi M and Taga Y 1997 IEEE Trans. Mag. 33 (5) 4367 